Material and Methods We retrospectively reviewed our prospectively maintained Neuro IR database and identified all patients who underwent transradial access for their diagnostic or interventional procedure between May 2019 and January 2021. Patient demographics, clinical information, procedural and radiographic data were collected.

Results We identified 749 patients in whom transradial access was obtained for either diagnostic and interventional Neuro IR procedures. Access was obtained using a 5F/6F/7F radial sheath. In some procedures, the sheath was exchanged for the guide catheter which was then inserted in a bareback (sheathless) fashion. Interventional procedures performed included carotid artery stenting, stroke thrombectomy, intracranial stenting, thrombolysis for central retinal artery occlusion, aneurysm treatment (with coiling or stent-assisted coiling, flow diverters or Woven EndoBridge device placement), vasospasm treatment, arteriovenous malformation and dural arteriovenous fistula embolization, middle meningeal artery embolization, and spinal angiography with embolization. A total of 12 access site complications were recorded (1.6\%) with 4 access site hematomas, 3 inflammatory changes at the puncture site, 2 asymptomatic radial artery occlusions, 2 radial artery injuries (1 self-limiting wire perforation and 1 perforation which was coiled via transfemoral route without any clinical sequela) and 1 retained broken microwire which was successfully removed in a subsequent session. None of the complications resulted in permanent local or neurological deficits.

Conclusion The transradial approach for diagnostic and interventional Neuro IR procedures is a safe vascular access choice.

Disclosures A. Kuhn: None. J. Singh: None. A. McGowan: None. M. Kirk: None. F. Massari: None. K. de Macedo Rodrigues: None. V. Naragum: None. V. Anagnostakou: None. M. Gounis: 1; C; National Institutes of Health (NIH), the United States - Israel Binational Science Foundation, Anaconda, ApicBio, Axovant, Cerenovus, Cook Medical, Gentuity, Imperative Care, InNeuroCo, Magneto. 2; C; Cerenovus, Imperative Care, phenox, Medtronic Neurovascular, Route 92 Medical, Stryker Neurovascular. 4; C; Imperative Care, InNeuroCo and Neurogami. A. Puri: 1; C; NIH, Stryker Neurovascular, Medtronic, Cerenovus. 2; C; Microvention, QApel, Perfuze Medical, Arsenal Medical, Merit Medical, Stryker Neurovascular, Medtronic, Cerenovus. 4; C; InNeuroCo Inc, Galaxy therapeutics, Agile Medical, Perfuze medical and NTI.

\section{E-123 EVALUATION OF SAFETY AND EFFICACY OF TRANSRADIAL ACCESS FOR MECHANICAL THROMBECTOMY INACUTE ISCHEMIC STROKE - A SINGLE CENTER EXPERIENCE}

${ }^{1} \mathrm{~A}$ Kuhn, ${ }^{1} \mathrm{~J}$ Singh, ${ }^{2} \mathrm{~K}$ de Macedo Rodrigues, ${ }^{1} \mathrm{~F}$ Massari, ${ }^{1} \mathrm{~F}$ Massari, ${ }^{1} \mathrm{M}$ Gounis, ${ }^{1} \mathrm{~A}$ Puri ${ }^{*}$. ${ }^{1}$ Division of Neurointerventional Radiology, Department of Radiology and New England Center for Stroke, University of Massachusetts, Worcester, MA; ${ }^{2}$ Greensboro Radiology, Greensboro, NC

\subsection{6/neurintsurg-2021-SNIS.218}

Purpose To evaluate the safety and efficacy of transradial (distal radial (snuffbox) and radial artery) access for mechanical thrombectomy in patients presenting with acute ischemic strokes.

Material and Methods Retrospective review of our prospectively maintained Neuro IR database and identification of all patients who underwent mechanical thrombectomy for anterior and posterior circulation strokes between January 2019 and November 2020. Information on patient characteristics, site of occlusion, catheter set up, TICI recanalization status, and patient outcome at 3 months was collected.

Results A total of 256 anterior $(n=239)$ and posterior $(n=17)$ circulation strokes were identified between January 2019 and November 2020. Of those, 17 were performed via transradial access (6.6\%), with 8 strokes located in the anterior and 9 in the posterior circulation. Eight patients were female. Mean age of anterior circulation stroke patients was 73.9 years (range 46-96 years) and 57.9 years (range 35-76 years) for posterior circulation stroke patients. Most occlusions were seen in the middle cerebral and basilar arteries. The NIHSS ranged between 5 to 24 for anterior circulation strokes (mean NIHSS 13) and 2 to 38 for posterior circulation strokes (mean NIHSS 12). Four patients received IV tPA. Ten procedures were performed via radial artery access and 7 procedures via distal radial artery (snuffbox) access. No conversion to femoral access was needed. Successful recanalization with TICI equal to or higher than $2 \mathrm{~B}$ was achieved in $87.5 \%$ of anterior circulation and $100 \%$ of posterior circulation thrombectomies. TICI $2 \mathrm{C}$ and 3 was achieved in $75 \%$ of anterior circulation and $88.9 \%$ pf posterior circulation thrombectomies. Single pass TICI $2 \mathrm{c}$ and 3 was seen in $7 / 17$ cases $(41.2 \%)$. The Infinity (Stryker) and Benchmark (Penumbra) catheters were mainly used as guide catheters. Intermediate catheters used included the 5F Sofia distal access catheter (Microvention), Large Bore aspiration catheter (Cerenovus) and Catalyst 6 (Stryker). A stent retriever, either Trevo (Stryker) or Solitaire (Medtronic), was used in all cases. No access site complication was noted.

Conclusion Transradial access for mechanical thrombectomy in acute ischemic stroke is a primary access in tortuous vasculature/posterior circulation strokes and is a good alternative to the femoral approach. This vascular access is especially helpful in patients with posterior circulation strokes, on anticoagulation or with large body habitus.

Disclosures A. Kuhn: None. J. Singh: None. K. de Macedo Rodrigues: None. F. Massari: None. F. Massari: None. M. Gounis: 1; C; National Institutes of Health (NIH), the United States - Israel Binational Science Foundation, Anaconda, ApicBio, Axovant, Cerenovus, Cook Medical, Gentuity, Imperative Care, InNeuroCo, Magneto. 2; C; Cerenovus, Imperative Care, phenox, Medtronic Neurovascular, Route 92 Medical, Stryker Neurovascular. 4; C; Imperative Care, InNeuroCo and Neurogami. A. Puri: 1; C; NIH, Stryker Neurovascular, Medtronic, Cerenovus.. 2; C; Microvention, QApel, Perfuze Medical, Arsenal Medical, Merit Medical, Stryker Neurovascular, Medtronic, Cerenovus.. 4; C; InNeuroCo Inc, Galaxy therapeutics, Agile Medical, Perfuze medical and NTI.

\section{E-124 PIPELINE EMBOLIZATION DEVICE WITH SHIELD TECHNOLOGY IN THE TREATMENT OF RECURRENT CEREBRAL ANEURYSMS USING LVIS STENT}

${ }^{1} \mathrm{~K}$ Takayama*, ${ }^{1} \mathrm{~T}$ Wada, ${ }^{1} \mathrm{H}$ Kishida, ${ }^{2} \mathrm{~K}$ Myouchin, ${ }^{3} \mathrm{~K}$ Kichikawa. ${ }^{1}$ Department of Interventional Neuroradiology/Radiology, Kouseikai Takai Hospital, Tenri, Japan; ${ }^{2}$ Department of Radiology, Nara Medical University, Kashihara, Japan; ${ }^{3}$ Department of Radiology, Nara Medical University, Kashihara, Japan

10.1136/neurintsurg-2021-SNIS.219 